ORIGINAL ARTICLES

\title{
Information searching behaviors among Vietnamese students during first wave of the COVID-19 pandemic
}

\author{
Nguyen Hoang Thuy Linh ${ }^{1}$, Tran Xuan Minh Tri ${ }^{1 *}$, Nguyen Thi Mien Ha ${ }^{1}$, Hoang Dinh \\ Tuyen ${ }^{1}$, Tran Thi Mai Lien ${ }^{1}$, Vo Van Thang ${ }^{1,2}$
}

\begin{abstract}
Objective: This study aims to describe the COVID-19 related information searching behaviors and the relationship between those behaviors and the satisfaction with the COVID-19 related information searched on the Internet among university students during first wave of the COVID-19 pandemic in Vietnam.
\end{abstract}

Methods: A cross-sectional study was conducted by a web-based survey from April 25, 2020 to May 9, 2020. Convenient sample with the method of snowball sampling was applied, 1003 students were obtained totally. Multivariable logistic regression model was used to identify the associations between those behaviors and the satisfaction with the COVID-19 related information searched on the Internet.

Results: Search engines were the most popular sources used for online COVID-19 information seeking (95.3\%), followed by Social media (92.4\%) and News portals $(91.6 \%)$. About $90 \%$ of participants searched the information related to the current spread of the coronavirus, followed by symptoms of the COVID-19 (81.8\%) and individual measures to protect against infection (81.9\%). Vietnamese remains the main language of the sources with $70.3 \%$ of participants used. There's $45.8 \%$ of participant satisfied about the COVID-19 related information. The group of participants who sought information about prevention was 0.47 times less dissatisfied than the group that did not search.

Conclusion: There are significant associations between searching topics related to prevention and the COVID-19 related information satisfaction searched on the Internet. These results highlight the need for providing efficient information related to the COVID-19 pandemic as well as seriously consider focusing more on social media to better bring official information to the public.

Keywords: COVID-19, information searching behaviors, university students, satisfaction

\section{INTRODUCTION}

The pandemic outbreak of COVID-19 has imposed a critical situation of public health in the world (1). Then, health prevention behaviors were very important in stopping the spread of the virus. Accessing the accurate

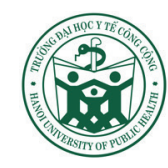

* Corresponding author: Tran Xuan Minh Tri Email:txmtri@huemed-univ.edu.vn

${ }^{1}$ Faculty of Public Health, Hue University of Medicine and Pharmacy

${ }^{2}$ Institute for Community Health Research, Hue University of Medicine and Pharmacy information sources, especially the official one has played a crucial role in practicing the right actions to protect ourselves during the pandemic. Although Vietnam reported its first case of COVID-19 on January 23, 2020, it reported only a little more than 300 cases and zero deaths over the following four months

Submited: 10 October, 2020

Revised version received: 10 November, 2020

Published: 26 March, 2021 
$(4,5)$. On January 9, the Ministry of Health first warned citizens of the threat; since then, the government has communicated frequently with the public, adding a short prevention statement to every phone call placed in the country, texting people directly, and taking advantage of Vietnam's high use of social media $(7,8)$. Therefore, technology has played a key role in the monitoring of suspected and confirmed infected patients, contributing to the overall success of Vietnam's pandemic prevention (6).

The Internet was the largest and fastest source to obtain health information, and millions of people seeking health information online every day (2). Access to accurate and up-todate information was essential for individual and collective decision making, especially at times of emergency (12). In the context of the COVID-19 pandemic, people around the world were forced to stay at home and turn to the Internet for work and to stay connected with others. As the COVID-19 outbreak has continued, the need to obtain information about the disease, its prevention, and risk communication has become greater for people. Mass media have been cited as a promising means with which to provide health-related information that potentially impacts audiences' behavioral outcomes on a large scale $(10,11)$.

Therefore, research on online health-seeking behaviors during a pandemic has played a crucial part, especially for the students, who have to miss school for a long time because of COVID-19 and are heavily affected by the pandemic. However, there are not many studies on this issue in Vietnam as well as in the world. This study aims to describe the COVID-19 related information searching behaviors and the associations between those behaviors and the satisfaction with the COVID-19 related information searched on the Internet among university students during first wave of the COVID-19 pandemic in Vietnam.

\section{METHODOLOGY}

\section{Design}

Cross-sectional study.

\section{Time and location}

The study was conducted through an online survey from April 25, 2020 to May 9, 2020 the time after the social distancing due to the COVID-19 was loosened in Vietnam and life is gradually back to normal.

\section{Subjects}

Undergraduates or graduate students of the Vietnamese universities, aged 18 years or older and living in Vietnam during the survey period and be able to access the online form.

\section{Sampling method}

Convenient sample with snowball sampling method was applied. Students were encouraged to widely share the survey link for other participants. Sample size was all participants completing the online questionnaire during collecting data period. Finally, 1003 students were obtained.

\section{Variables}

Dependent variable: The satisfaction about the information searched on the Internet for Coronavirus includes 5 levels (very dissatisfied; dissatisfied; partly partly; satisfied; very satisfied).

The level of information satisfaction was divided into 2 groups: Dissatisfied (very dissatisfied, dissatisfied); Satisfied (very satisfied, satisfied, partly partly). 


\section{Independent variables:}

- Characteristics of study participants: sex (male, female, others); age group; field of study (medicine/health science, others);

- Sources used for online COVID-19 information seeking: the question includes 11 answer labels is adapted from Marstedt (2018) (17). The response includes 5 levels (often, sometimes, rarely, never, don't know) are recorded into 2 variables: Yes (often, sometimes) and No (rarely, never, don't know). These variables are combined into 3 groups: (1) Sources of information from the Government (Yes/No) includes Websites of public bodies, Guidebook-communities, Health portals, News portals. (2) Social media (Yes/No) includes Facebook, Instagram, Twitter, and YouTube. (2) Other online information channels (Yes/No) include Search engines, Wikipedia and other online-encyclopedias, Blogs on health topics, Websites of doctors or health insurance companies, Others. If the answer of the participants is "Yes" for at least one source among each group, it will be calculated as "Yes" for that group.

- Content of the searching information related to the Coronavirus: the question includes 10 answer options is adapted from COVID-19 Health Literacy Survey: University Students (COVID-HL Survey), questionnaire and scale documentation (18). The 10 answer options are combined into 3 groups: (1) Topic related to treatment (Yes/No) includes the current spread of the coronavirus, transmission routes of the coronavirus, symptoms of theCOVID-19. (2) Topic related to prevention (Yes/No) includes individual measures to protect against infection, hygiene regulations, restrictions. (3) Other topics (Yes/No) include current situation assessments and recommendations, economic and social consequences of the
Coronavirus, dealing with psychological stress caused by the Coronavirus. If the answer of the participants is "Yes" for at least one source among each group, it will be calculated as "Yes" for that group.

- Languages of the sources (Vietnamese, English, Both).

\section{Datacollection}

Data are collected in the form of online surveys by Microsoft Forms and shared on social networking(such as Email, Facebook, Zalo, etc.).

\section{Data analysis}

Descriptive analysis was used to describe the percentage of participant searching behaviors about the COVID-19 related information.

Multivariable logistic regression analysis by the enter method was utilized to evaluate the independent associations between the outcome variables (the satisfaction with the COVID-19 related information searched on the Internet) and those searching behaviors (including sources used for online COVID-19 information seeking, content of the searching information related to Coronavirus, languages of the sources) after adjusting the potential confounding variables (gender, age group, field of study) among universities students during first wave of the COVID-19 pandemic in Vietnam with 95\% confidence. The level $\alpha=0.05$ was used to determine as statistical significance results. Data were processed using SPSS 20.0 software.

\section{Research ethics}

The study was approved by the Medical Ethics Council of Hue University of Medicine and Pharmacy, approval number H2020/050 signed on April 20, 2020. Participant's information is for research purposes only. 


\section{RESULTS}

Table 1. Characteristics of study participants $(n=1003)$

\begin{tabular}{|c|c|c|c|}
\hline \multicolumn{2}{|l|}{ Characteristic } & \multirow{2}{*}{$\begin{array}{l}\mathbf{n} \\
300\end{array}$} & \multirow{2}{*}{$\frac{\mathbf{\%}}{29.9}$} \\
\hline Gender & Male & & \\
\hline & Female & 701 & 69.9 \\
\hline & Other & 2 & 0.2 \\
\hline \multirow[t]{3}{*}{ Age } & $<25$ & 917 & 91.4 \\
\hline & $\geq 25$ & 86 & 8.6 \\
\hline & Mean $\pm \mathrm{SD}$ & 21.4 & \\
\hline \multirow[t]{2}{*}{ Field of study } & Medicine/Health science & 842 & 83.9 \\
\hline & Others & 161 & 16.1 \\
\hline
\end{tabular}

Table 1 indicates the characteristics of belonged to medicine/health sciences groups. 1003 participants, of whom over two-third $91.4 \%$ of participants are under 25 years old. were females and over $80 \%$ of participants

Table 2. Sources used for online COVID-19 information seeking $(n=1003)$

\begin{tabular}{lll}
\hline & $\mathbf{n}$ & $\mathbf{\%}$ \\
\hline Sources of information from the Government & 984 & 98.1 \\
\hline Websites of public bodies & 758 & 75.6 \\
\hline Guidebook-communities & 501 & 50.0 \\
\hline Health portals & 713 & 71.1 \\
\hline News portals & 919 & 91.6 \\
\hline Social media & 737 & 73.5 \\
\hline Social media & 927 & 92.4 \\
\hline YouTube & 776 & 77.4 \\
\hline Other online information channels & 989 & 98.6 \\
\hline Search engines & 956 & 95.3 \\
\hline Wikipedia and other online-encyclopedias & 648 & 64.6 \\
\hline Blogs on health topics & 533 & 53.1 \\
\hline Websites of doctors or health insurance companies & 546 & 54.4 \\
\hline Others & 439 & 43.8 \\
\hline
\end{tabular}


Table 2 shows that search engines were the most popular sources used for online COVID-19 information seeking (95.3\%), followed by Social media (92.4\%) and
News portals (91.6\%). Besides, over $70 \%$ of participants used YouTube, websites of public bodies and health portals.

Table 3. Content of the searching information related the Coronavirus $(n=1003)$

\begin{tabular}{lll}
\hline & n & \% \\
\hline Related to treatment & 982 & 97.9 \\
\hline Current spread of the coronavirus & 951 & 94.8 \\
\hline Transmission routes of the coronavirus & 693 & 69.1 \\
\hline Symptoms of COVID-19 & 820 & 81.8 \\
\hline Related to prevention & 878 & 87.5 \\
\hline Individual measures to protect against infection & 821 & 81.9 \\
\hline Hygiene regulations & 610 & 60.8 \\
\hline Restrictions & 641 & 63.9 \\
\hline Other topics & 793 & 79.1 \\
\hline Current situation assessments and recommendations & 621 & 61.9 \\
\hline Economic and social consequences of the Coronavirus & 565 & 56.3 \\
\hline Dealing with psychological stress caused by the Coronavirus & 378 & 37.7 \\
\hline Others & 8 & 0.8 \\
\hline
\end{tabular}

About $95 \%$ of participants searched the information related to the current spread of the coronavirus, while the figures for symptoms of COVID-19 and individual measures to protect against infection were lower, at approximately $82 \%$.

Table 4. Languages of the sources $(n=1003)$

\begin{tabular}{lcc}
\hline & $\mathbf{n}$ & $\mathbf{\%}$ \\
\hline Vietnamese & 705 & $\mathbf{7 0 . 3}$ \\
\hline English & 6 & 0.6 \\
\hline Both & 292 & 29.1 \\
\hline
\end{tabular}

Vietnamese remains the main language of the sources with $70.3 \%$ of participants used, while
$0,6 \%$ of participants searched information by English only. 


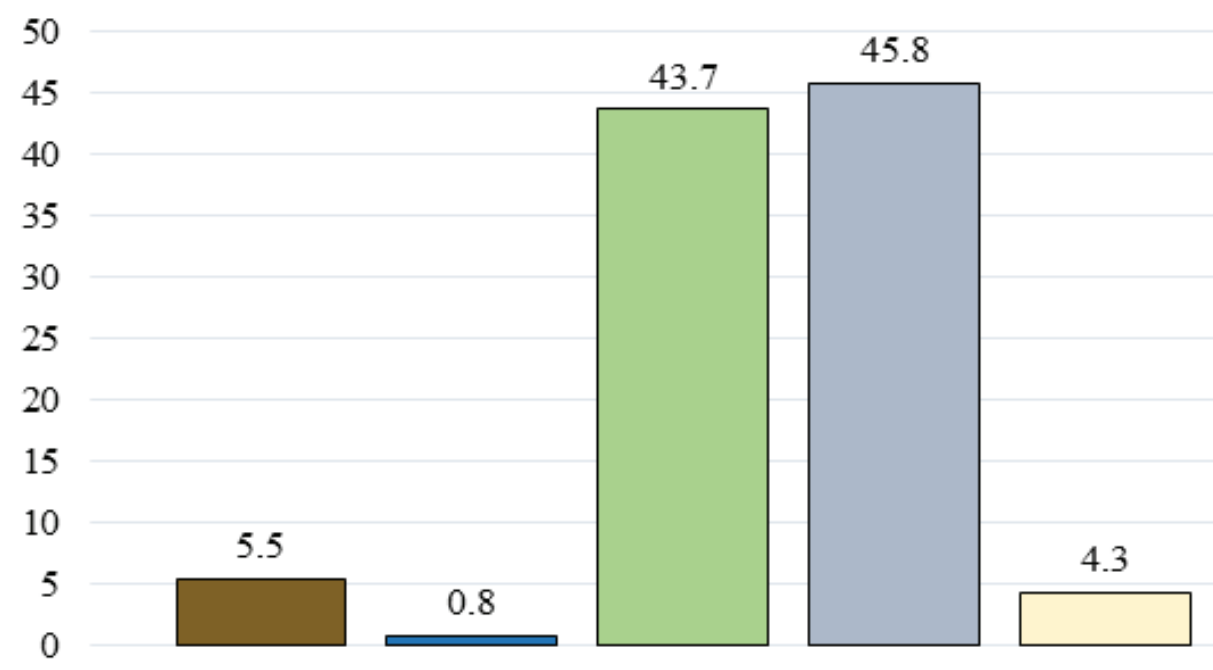

$\square$ Very dissatisfied $\square$ Dissatisfied $\square$ Partly partly $\square$ Satisfied $\square$ Very satisfied

Figure 1. COVID-19 related information satisfaction $(\%)(n=1003)$

The percentage of satisfied group is the very dissatisfied group's one are only $4.3 \%$ highest (45.8\%), while the very satisfied and and 5.5\%.

Table 6. Multivariable associations between the COVID-19 related information satisfaction and information searching behaviors among Vietnamese students during COVID-19 pandemic

\begin{tabular}{|c|c|c|c|}
\hline & & \multicolumn{2}{|c|}{ Dissatisfaction } \\
\hline & & $\operatorname{AOR}^{*}(95 \% \mathrm{CI})$ & $\mathbf{p}$ \\
\hline \multicolumn{4}{|l|}{ Information sources } \\
\hline \multicolumn{4}{|c|}{$\begin{array}{l}\text { Sources of information from the } \\
\text { Government }\end{array}$} \\
\hline & Yes & 1 & \\
\hline & No & $0.00(\mathrm{~N} / \mathrm{A})$ & 0.998 \\
\hline \multicolumn{4}{|l|}{ Social media } \\
\hline & Yes & 1 & \\
\hline & No & $0.71(0.37-1.38)$ & 0.308 \\
\hline \multicolumn{4}{|c|}{ Other online information channels } \\
\hline & Yes & 1 & \\
\hline & No & $0.00(\mathrm{~N} / \mathrm{A})$ & 0.999 \\
\hline \multicolumn{4}{|l|}{ Searching topics } \\
\hline Topic related to treatment & & & \\
\hline
\end{tabular}




\begin{tabular}{llcc}
\hline & No & 1 & \\
\hline & Yes & $0.60(0.15-2.33)$ & 0.459 \\
\hline Topic related to prevention & & & \\
\hline & No & 1 & \\
\hline Other topics & Yes & $0.47(0.24-0.94)$ & $\mathbf{0 . 0 3 4}$ \\
\hline & & & \\
\hline & No & 1 & 0.201 \\
\hline Yanguages & Yes & $1.57(0.79-3.15)$ & \\
\hline & & & 1 \\
\hline & Vietnamese & $1.48(0.80-2.76)$ & 0.213 \\
\hline
\end{tabular}

*AOR (adjusted Odd Ratio): adjusted for the characteristics of study participants (gender, age group, field of study).

There are significant associations between searching topics related to prevention and the COVID-19 related information satisfaction when searching on the Internet $(p<0.05)$. The group of participants who did seek information about prevention was less dissatisfied than the group that did not search. $(\mathrm{AOR}=0.47$ (95\%CI: 0.24-0.94)).

\section{DISCUSSIONS}

\section{Sources used for online COVID-19 information seeking}

The Search engines were the most popular sources used for online COVID-19 information seeking $(95.3 \%)$, following by Social media $(92.4 \%)$ and News portals (91.6\%). Besides, over $70 \%$ of participants used YouTube, Websites of public bodies and Health portals. In the light of the research in Bahrain which showed that the highest respondents' information reliance was associated with the source of "social media accounts of official health organizations", followed by "health care professionals" (3). Another study showed that social media has played a significant role in affecting the public during the COVID-19 crisis, which $82.6 \%$ of participants used Facebook - the biggest social media in the world (13). In Indonesia, social media was the most widely accessed source of information besides online media and television (19). According to a research in China, mobile social networking apps (MSNs) were the most commonly used, followed by online news media and social media (20).

In Vietnam, there were 64 million active Facebook users and 80 percent of smartphone users in Vietnam had the local social media apps $(7,8)$. With a strong and widespread power and attracting a large number of users, social media was becoming an effective communication channel, updating the epidemic's developments as well as how to prevent COVID-19. Therefore, health policymakers should seriously consider focusing more on social media to better bring official information to the public. Apart from providing accurate and regular information about the pandemic to people through daily news portal, 
the Government should step up to supply the trustworthy results in the search engines.

\section{Topic of the searching information about Coronavirus and related topics}

About $95 \%$ of participants searched the information related to the current spread of the coronavirus, following by symptoms of the COVID-19 (81.8\%) and individual measures to protect against infection (81.9\%). According to a research using Google Trends to explore the Internet search activity related to COVID-19 from January to March 2020, information related to the symptoms of the COVID-19 is in the top five searches related to health at that time (15). Another study from Ahmed E. also showed that the information about symptoms of the disease and individual measures to protect against infection also occupy the rank 3 and 4 among the list of most popular information about COVID-19 (3).

People seeking for information about the current spread of the virus, the symptoms of the disease and individual measures to protect against infection during the pandemic can be explained that these are the most basic information about the pandemic that the Government always remind, thereby helping people to be able to protect themselves from the infection with the virus.

\section{Factors associated with the information satisfaction during COVID-19 pandemic}

Multivariate logistic regression model showed that the group of participants who sought information about prevention was 0.47 times less dissatisfied than the group that did not search. The reasons can be explained that the people who sought information about how to prevent themselves from coronavirus such as individual measures to protect against infection, hygiene regulations and restrictions will have an accurate knowledge about the prevention, from which they can select the appropriate information and make decisions to better protect their health. A lack of adequate knowledge is probably the driving force for the public panic, particularly at the early stages of an outbreak (19). Therefore, it was essential for everyone to have full access to information about the pandemic, especially information related to prevention not only about physical health but also mental health during the pandemic.

Some limitations of the study include: the research subjects cannot represent all students in Vietnam. This research is based on Internet-based data collection so students in areas without the Internet cannot access it. The accuracy of the information provided by the subject has not been verified. A cross-sectional study cannot draw causal conclusions of the research problem.

\section{CONCLUSIONS AND RECOMMENDATIONS}

During first wave of the COVID-19 pandemic in Vietnam, search engines and social media were two of top popular sources used for online COVID-19 information seeking, while information related to the current spread of the coronavirus, symptoms of the disease COVID-19 and individual measures to protect against infection were the most popular topics. Vietnamese remains the main language of the sources. There are significant associations between searching topics related to prevention and the COVID-19 related information satisfaction when searching on the Internet. These results highlight the importance of providing accurate and reliable information related to the COVID-19 pandemic. Therefore, the government needs to diversify official communication sources 
to the people, especially on social media platforms in order to help people access the information in the most effective way.

\section{REFERENCES}

1. World Health Organization (2020 Coronavirus Disease (COVID-19) - events as they happen. Available from: https:/www.who.int/ emergencies/diseases/novel-coronavirus-2019/ events-as-they-happen

2. International Telecommunications Union/ UNESCO. The state of broadband 2017: broadband catalyzing sustainable development. [cited 2017 Aug 01]. Available from: https:// www.itu.int/dms_pub/itu-s/opb/pol/S-POLBROADBAND.18-2017-PDF-E.pdf

3. Ebrahim AH, Saif ZQ, Buheji M, AlBasri N, Al-Husaini FA, Jahrami H (2020). COVID-19 Information-Seeking Behavior and Anxiety Symptoms among Parents. OSP J Health Car Med 1. HCM-1-105

4. COVID-19 update. Vietnam Ministry of Health website. [cited 2020 May 23]. Available from: https://ncov.moh.gov.vn/.

5. Max Roser, Hannah Ritchie, Esteban OrtizOspina and Joe Hasell (2020). Coronavirus Pandemic (COVID-19). Available from: https:// ourworldindata.org/coronavirus

6. To Trieu Hai (Tracy) Ly. How Vietnam is Winning its War Against COVID-19. [cited 2020 April 6]. Available form: https://www. asiapacific.ca/publication/how-vietnamwinning-its-war-against-COVID-19.

7. La V-P, Pham T-H, Ho M-T, et al. Policy response, social media and science journalism for the sustainability of the public health system amid the COVID-19 outbreak: the Vietnam lessons. Sustainability. 2020;12(7):2931.

8. Todd Pollack, et at. Emerging COVID-19 success story: Vietnam's commitment to containment. As part of the Exemplars in Global Health platform. [cited 2020 June 30] Available from: https://ourworldindata.org/ covid-exemplar-vietnam.

9. Tomasz Szmuda, Shan Ali, Tarjei Vevang Hetzger, Philip Rosvall, Paweł Słoniewski. Are online searches for the novel coronavirus (COVID-19) related to media or epidemiology? A cross-sectional study. International Journal of Infectious Disease 95(2020): 192-197.
10. Gesualdo F, Romano M, Pandolfi E, et al. Surfing the web during pandemic flu: availability of World Health Organization recommendations on prevention. BMC Public Health 2010; 10:561.

11. Xavier AJ, d'Orsi E, Wardle J, et al. Internet use and cancer-preventive behaviors in older adults: findings from a longitudinal cohort study. Cancer Epidemiology Bio- markers \& Prevention 2013; 22:2066-2074.

12. Makhortykh, M.; Urman, A.; Ulloa, R. (2020). How search engines disseminate information about COVID-19 and why they should do better. The Harvard Kennedy School (HKS) Misinformation Review. Volume 1, Special Issue on COVID-19 and Misinformation.

13. Ahmad AR, Murad HR. The Impact of Social Media on Panic During the COVID-19 Pandemic in Iraqi Kurdistan: Online Questionnaire Study. J Med Internet Res 2020;22(5):19556.

14. Rovetta A, Bhagavathula AS. COVID-19Related Web Search Behaviors and Infodemic Attitudes in Italy: Infodemiological Study. JMIR Public Health Surveil 2020;6(2):19374.

15. Coronavirus: Student Satisfaction Begins to Slip. [cited 2020 Jul 8]. Available from: https:// www.youthsight.com/blog/student-satisfactionbegins-to-slip-amid-coronavirus

16. Dadaczynski K, Okan O, Rathmann K.COVID-19HealthLiteracy Survey:University Students (COVID-HL-Survey). Questionnaire and Scale Documentation. Version 1. Bielefeld / Fulda: Bielefeld University, Interdisciplinary Center for Health Literacy Research and Fulda University of Applied Sciences, Public Health Center; 2020.

17. Iman. (2020). Survei Kedaikopi: Mayoritas Masyarakat Indonesia Anggap Virus Corona Ancaman Serius. [cited 2020 Mar 05]. Available from: https://rri.co.id/nasional/796708/surveikedaikopi- mayoritas-masyarakat-indonesiaanggap-virus-corona-ancaman-serius

18. Piper Liping Liu. COVID-19 Information Seeking on Digital Media and Preventive Behaviors: The Mediation Role of Worry. Cyberpsychology, Behavior, and Social Networking. 2020 Oct;23(10):677-682

19. Wen Wang, Qiao He, Mei Liu, Mingqi Wang, Xin Sun. COVID-19: lack of knowledge is driving public panic. [cited $2020 \mathrm{Feb} 28$ ]. Available from: https://blogs.bmj.com/bmj/2020/02/28/ communicating-research-evidence-aboutCOVID-19-to-reduce-public-panic/ 